\title{
Effects of social media on relationships in Lebanon: A study case for Lebanon
}

\author{
Alia Ghaddar \\ Lebanese International University \\ Beirut, Lebanon \\ alia.ghaddar@liu.edu.lb
}

\author{
Mouhamad Hamadani \\ Lebanese International University \\ Beirut, Lebanon \\ 11230347@students.liu.edu.Ib
}

\author{
Fadi Yamout \\ Lebanese International University \\ Beirut, Lebanon \\ fadi.yamout@liu.edu.lb
}

\begin{abstract}
Modern technology provides great access to information. With the development of communications technologies, the nature of information changed from retrieving simple documents to accessing visual-based social media, digital platforms, video-streaming, and music. In that process, search engines and social media platforms like Google, Facebook, Twitter and so on, are used to locate information and to connect with other people, and businesses. It is a platform to learn more about people we associate with and expose aspects of our lives that were previously hidden such as dates, family gatherings, nights out and so on. It is also affecting our relationships with friends and family members. This study aims to investigate the effect of social media and technological tools on the relationship between couples and among family members in Lebanon. We examine whether people are becoming more interested in technology than in people around them and consequently are losing real-life connection. The study is based on the time spent on social media, its effect on the relationship, and how much it contributes to marital problems, emotional disrespect, cheating, breakup, divorce, and others.
\end{abstract}

Keywords: Social Media, interpersonal communication, internet addiction, social comparison

\section{INTRODUCTION}

Information and communication technology has changed rapidly over the past 20 years. With the rise of high speed internet connections and web enabled cell phones, it is easier than ever to find and access information on the Internet. The emergence of social media platforms such as Facebook, Twitter, Snapchat and Instagram has played a very important part in ensuring that we stay connected with our near and dear ones. It made the interaction between people faster with the least amount of effort for socializing.

The first and main advantage brought for society is connectivity. Regardless of the location and ethnicity, people from anywhere can connect with anyone to learn and share thoughts. These technologies have taken an essential part in people's day-to-day lives and being without them would be unimaginable for some of us.

As more people depend on the Internet for information and support, it is important to ensure that people understand both the positive (support groups, access to information) and negative (misinformation, cyberbullying) aspects of the Internet and social media. The impact of social media on families has been researched to see what negative and positive effects are happening.
In this paper, we conduct a survey on the time spent online and it is effect on relationships in Lebanon.

\section{OBJECTRIVE OF THE STUDY}

The main objective of the paper is:

(i) To analyse the impact of Social media as a mean of communication tool

(ii) To assess the effect on couples relationship

(iii) To assess the effect on Parent/kids relationship

(iv) How much control do parents have over their children's activities on social media?

\section{INTERNET AND SOCIAL MEDIA}

Communication is increasing across cultures. There are a variety of platforms that can be used for socialising such as Facebook, Instagram, Twitter, etc. The number of social networks users has increased very fast in the past years and continues to grow. According to statista (Clement, J. 2019), 0.97 billion of people worldwide were using social networks in 2010. By 2021 there will be 2.9 billion users (Figure 1). Figure 2 shows the number of active users (in millions) as of July 2019 (Clement, J. 2019). Internet and Social Media can 
be used for a variety of different reasons: Being in touch, Business, sharing information/thoughts and experience. However, everything in the world has good aspects as well as negative aspects. Social media has many positive and negative aspects (Betul et al., 2019).

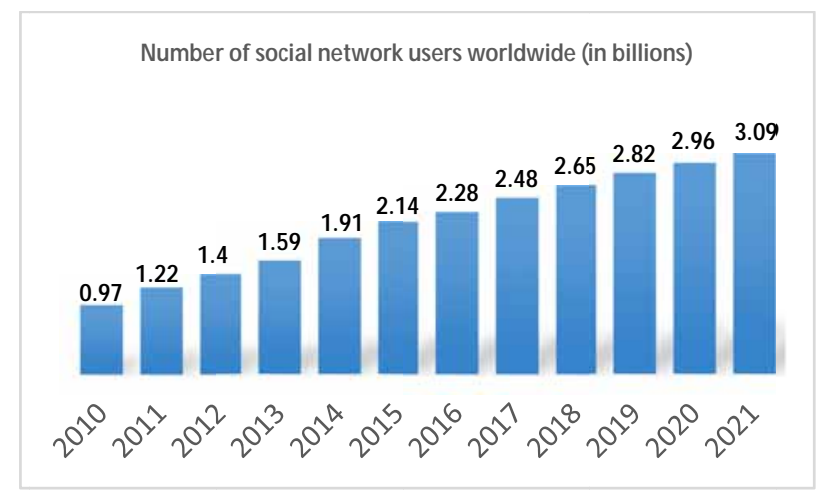

Figure 1: Number of social network users worldwide from 2010 to 2021 (in billions)

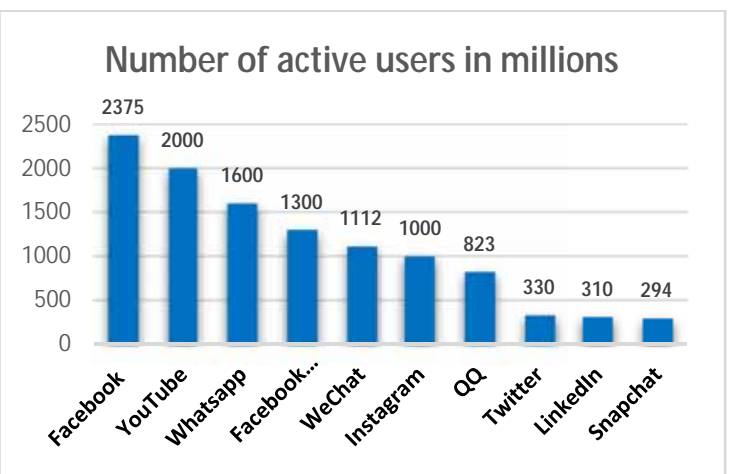

Figure 2: Number of active users (in millions) as of July 2019

\subsection{Positive aspects of Social Media}

Social media offers many opportunities, in addition to ensuring connectivity between people all over the world. It can help them share experience, spread awareness (Gaál et al., 2015). Social media has also gained credibility over the years where many connect with experts on topics via Social Media (Yunis et al. 2019) and share knowledge (Dušan et al., 2018; Saadiah et al., 2016).

Patients and their families use social media technol ogies to share their experiences and their findings and educate others with similar conditions (Shashi et al., 2016).

Authors in (Maged et al., 2016) briefly describe the main issues surrounding the uses of Instagram and WhatsApp in health and medicine. Healthcare organizations, clinicians and patients can benefit from the use of social media through education, obtaining information, performing research, receiving support. It can help patient understand their healthcare requirements and improves their engagement and empowerment (Mouseh et al., 2014).

In the business world and along with the technology revolution, companies become under pressure to go digital via e-business (Bahareh \& Najafi, 2017). It can help reach a high number of potential customers, increase sales, provides greater customer engagement and feedback. It improves networking opportunities with them, and offers many opportunities in marketing (Helena et al. 2018), tourism operations and management (van der Bank, 2015).

\subsection{Negative aspects of Siocial Media}

The great dependence on new technologies and spending excess time on social networking sites could be adversely affecting a person's mood. A recent study conducted in Montreal (Boers et al., 2019) revealed that one of the biggest causes of depression among teenagers was not video games but rather social media, or the excessive time spent on Social media. For the authors of this study, Instagram was found guilty because of the fact that teens that use it often compared their lives to the unrealistic perfect lives that others show on Instagram. Users craft their profiles using selfpresentation tools to control and manipulate the impressions others form of them. This leads others to have negatives feeling about themselves. Social media can become extremely addictive as some individuals are more worried about portraying a perfect life on their social media profile, rather than actually experiencing it. In (Demetrious, I., 2019), Author say that many users show an identity on the virtual world that deviates from their true-self life. The work found a significant relationship between the representations of the self-image in online posts with a happy life, and depressive symptoms. On the other hand, a research team from university of oxford (Amy et al., 2019), highlights that family and school life play a very integral role when it comes to the overall wellbreing of any adolescence.

Families have different parenting styles that determine how much parents bond with their children. The excessive usage of social media, internet and the web may lead to addiction and in some extreme cases, users are forced to attend rehab centres to get over their social media addictions and to help return to a normal life. In South Korea for example, a rehab camp for Internet-addicted teenagers offers stress-reduction classes and non-tech activities, such as walking, table tennis, card games and music learning. The center is called the National Centre for Youth Internet Addiction Treatment. In Washington, reSTAR clinic helps people with facebook addiction disorder to be treated in a 45-day program to wean them off their online addictions. 
In this age of social networking, parental supervision is as valuable online as it is offline. The role of parents is to be aware and not let the child escape the reality by submerging oneself in the illusion created by the social media. According to authors in (Constantine \& Musingafi, 2013), the parenting styles play a key role in determining how much children use social media. Permissive parenting do not set limits and is linked to risky children behaviours. On the other hand, authoritarian parenting styles generally lead to children who are obedient and proficient but they rank lower in happiness, social competence and self-esteem because they fear punishment from parents.

Psychologists are increasingly concerned that technology is breaking down family communication. Distracted parents or partners who compare their significant others and life in general to the digital lives of other friends/connections on social media might has impacted their self-esteem (Muqaddas et al., 2017) and family relationship in a negative way (Frampton \& Fox, 2018; Carter, 2015). It was stated that partners who cheated on their partner often reported that their own infidelity had been facilitated by social media sites (Carter, 2015; Abbasi \& AlGhamadi, 2017). Authors in (Abbasi \& AIGhamadi, 2017) state that the American Association of Matrimonial Lawyers claimed in the past years that an increasing number of divorce cases cite Facebook as a contributing factor in the dissolution of marriage. An increase in the Facebook use during the same period is positively correlated with a corresponding increase in divorce rates (Valenzuela et al., 2014). Implications for couples and therapists were discussed in (Jason et al., 2016). Results indicated that partners who have a loving real-life relationship actually participate in less Facebook Maintenance behaviours, and couples who participate in more Facebook Maintenance behaviours experience less love in the relationship.

\section{METHODS}

This study incorporates a mixed-method approach which includes a survey of quantitative Likert-like questions and several qualitative short answer questions. The sample for this study included social media users between 18-64 years of age. The survey is made up of several scales. The first scale measures the participants' perceived levels of social media use and purposes. Questions included "1. How often do you use Facebook or other social networking applications (WhatsApp, Instagram, Twitter, Snapchat)?", "2. How often do you view friends' profiles on Facebook?", "3. Do you take your phone to bed?". Participants answered questions such as " 1 . I feel lost without my mobile phone", "2. My productivity has decreased as a direct result of the time I spend on the mobile phone".

The second scale measures social media related conflicts between people. The five questions included: "1. How often do you have an argument with your significant other as a result of excessive use of Facebook, Snapchat, WhatsApp, etc.?", "2. How often do you post photos of you with your partner on social media", etc. To assess technology as a source of tension between couples and family members, a list of questions were combined such as: "1. How often did you have an argument with your spouse or partner about the amount of time one of you was spending online (Facebook, WhatsApp, Instagram, etc..)?"

"2. How often did you feel your spouse or partner was distracted by their cell phone or technological device when you were together?", "3. My friends and family complain about my use of the mobile phone.", "4. How frequently do you have a discussion with your children because of content they or a friend posted on a social network?"

The third scale is used to measure the childparent/family attachment. Participants answered questions such as: " 1 . Do you have meals regularly with your kids and/or partner together?", "2. Do you allow your kids to use technological gadgets when everyone in your family is together?", "3. Do you have a home technology policy with your kids or spouse (house rules or guidelines about cell phones and/or technological gadgets use)?", "4. How frequently do you have a discussion with your children because of content they or a friend posted on a social network?".

\section{RESULTS}

The sample size for this study was 100 participants. The age varied as follows: $47 \%$ have age between $25-34,19 \%$ have age between $18-24$, There were $62 \%$ females Lebanese and $38 \%$ males Lebanese participants. Of this sample, $57 \%$ of participants always take their phone to bed. $18 \%$ of the answers were very often. Only 13\% keep their phone away when they go to sleep or rarely take it to bed (see Table 1)

هل تأخذ هاتفك إلى السرير؟ Table 1. Do you take your phone to bed?

\begin{tabular}{|c|c|}
\hline Always / دائماً & $57 \%$ \\
\hline أبدا / Never & $4 \%$ \\
\hline Rarely / نادر أ & $9 \%$ \\
\hline Sometimes أحياناً & $12 \%$ \\
\hline غالباً / Very Often & $18 \%$ \\
\hline Total & 100 \\
\hline
\end{tabular}

$63 \%$ of population find it difficult to switch off their phone (see Table 2). Answers were as follows: 
Always $(40 \%)$, Very Often $(10 \%)$, Sometimes (13\%), Rarely (14\%), Never (23\%).

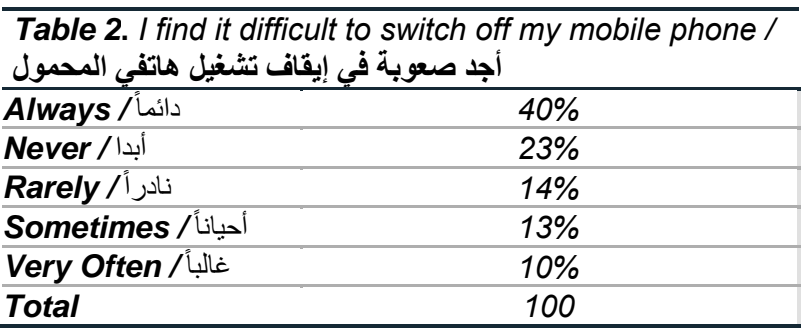

More than $50 \%$ of the population feel lost without their mobile phone (see Table 3). Answers were as follows: Always (42\%), Often (10\%), Sometimes $(20 \%)$, Rarely $(9 \%)$, Never (19\%).

Table 3. I feel lost without my mobile phone / أشعر المحمول هاتفي دون بالضياع

\begin{tabular}{|c|c|}
\hline Always / دائهاً & $42 \%$ \\
\hline أبدا / Never & $19 \%$ \\
\hline Rarely / نادر R & $9 \%$ \\
\hline Sometimes / أحياناً & $20 \%$ \\
\hline غالباً / Very Often & $10 \%$ \\
\hline Total & 100 \\
\hline
\end{tabular}

\section{Research Questions/Hypotheses}

We set the following Research Questions/Hypotheses:

Research Q1: How does the use of social media influence the quality of the user's interpersonal relationships?

Research Q2: How does the use of social media influence the user's overall emotional wellbeing and family attachment?

Four hypotheses were tested to strengthen our understanding of the relationship between social media and relationships

\section{- Hypothesis 1: "Excess usage of Social Media is a source of tension"}

This hypothesis stated that increased time spent on social media would lead to decreased overall quality of the users' interpersonal relationships. A Spearman's rho correlational analysis was conducted to examine the relationship between the amount of time spent on social media SOCIAL MEDIA and the increase of tension in the user's interpersonal relationships. The analysis significance is $r(100)=0.252, p=0.011<0.05$. The test verified that for participants who spent more time on social media the quality of their relationship decreased, in other words the tension in relationship increased.

- Hypothesis 2: Social media influences on Loosing the "Us time"
A difficulty to avoid social media can make someone fail to notice his surroundings, including his/her partner. A moment that should have been spent together is replaced by each of them scrolling down the social media's pages. No wonder it often triggers a conflict.

This hypothesis stated that increased time spent on social media would lead to the user's decreased overall emotional well-being in couple. A Spearman's rho correlational analysis was conducted to examine the relationship between the amount of time spent on social media and the user's couple connection. The analysis was significant, $r(100)=0.413, p<.01$. It indicates that for those whose partner spent more time on social media, tends to experience negative emotions towards their current relationship. $54 \%$ were upset that their partners is distracted by their technological device when they are together. A $2 * 2$ experimental design was assess using a factorial ANOVA. It was found that targets who spent time on social media have significantly more conflict $(M=3, S D=1.30)$ with their significant other for being distracted when they are together. This analysis was significant, $F(4,83)=6.236, p<.01$.

\section{- Hypothesis 3 "Social Media makes it easier for couples to cheat"}

As stated in (Abbasi \& AIGhamadi, 2017), flirtation with a spouse has positive benefits; however, a partner's intentional engagement in extra online flirtation leads to loss of trust and is also damaging to the committed relationship. $78 \%$ of the population agree that online flirtations or relationships count as cheating. $76 \%$ of participants says that technology makes it easier for couples to cheat. $15 \%$ were neutral and $9 \%$ disagreed (see Table 4). A $2 * 2$ experimental design was assess using a factorial ANOVA. It was found that targets who gotten upset at something that they found out their spouse or partner was doing online, tend to compare their own marriage or couple relationship with the ones of others $F(1,96)=5.902, p<.01$. They also agree that Technology makes it easier for couples to cheat $(p<0.01) .35 \%$ of the participants broke up before with someone because of social media online cheating or flirtation.

We found that there is no relation between gender and this opinion about cheating, $r(100)=0.27$, $p=0.788$.

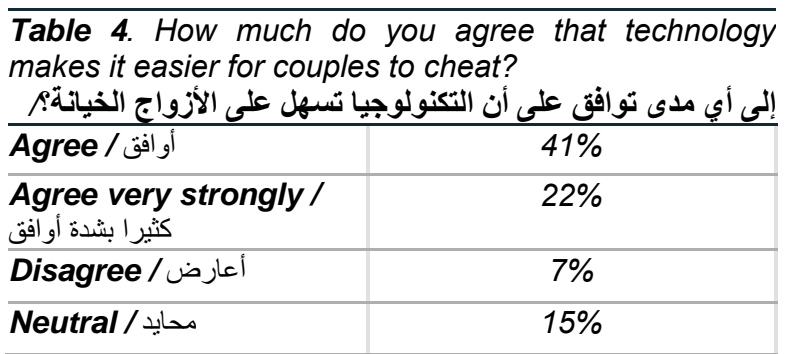




\begin{tabular}{l|c|}
\hline Strongly agree / بشدة موافث & $13 \%$ \\
\hline $\begin{array}{l}\text { Strongly disagree / } \\
\text { بشدارة }\end{array}$ & $2 \%$ \\
\hline Total & 100 \\
\hline
\end{tabular}

Technology is often painted as the enemy of meaningful relationships. Although that research studies have shown that technology can help couples manage their conflict better, communicate better, and feel closer to one another (Piercy et al., 2015). They are also recommending couples use technology when angry with one another in order to slow down their response times and give them space to cool off.

We noticed that $34 \%$ of the population say that they resolved arguments with their partner online or by text message that they were having difficulty resolving in person. $51 \%$ said that they have felt closer to their spouse or partner because of exchanges they had online or via text message (Figure 3).

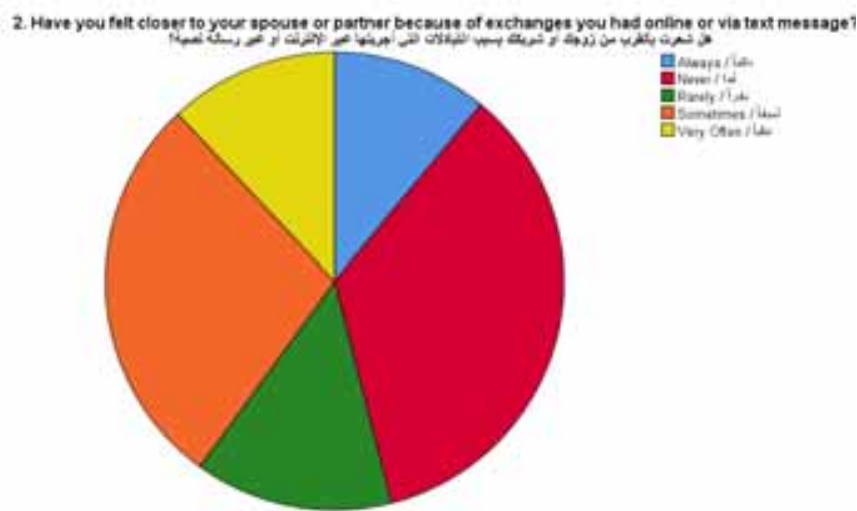

Figure 3: "Have you felt closer to your spouse or partner because of exchanges you had online or via text message?". Answers are: $11 \%$ Always, $35 \%$ never $14 \%$ Rarely, 28\% Sometimes, $12 \%$ Very Often.

\section{- Hypothesis 4: "Social Media/technology isolates kids from their parents"}

For many people in the younger generations, social sites are getting important when it comes to catching up with friends, checking on people's lives, etc. $76 \%$ of the population agree that the technology isolates kids from their parents. We found that $46 \%$ don't have a home technology policy with their kids or spouse (house rules or guidelines about cell phones and/or technological gadgets use).

A $2 * 2$ experimental design was assess using a factorial ANOVA. It was found that targets who spent more time using their mobile phone, extremely agree that the technology isolates kids from their parents $F(4,11)=4.157,(p<0.027)$.

$90 \%$ of participants who have kids that use technological devices, rarely have discussion with their children because of content they posted on a social network. However, $41 \%$ do not allow their kids to use technological gadgets when everyone in family is together (Figure 4).

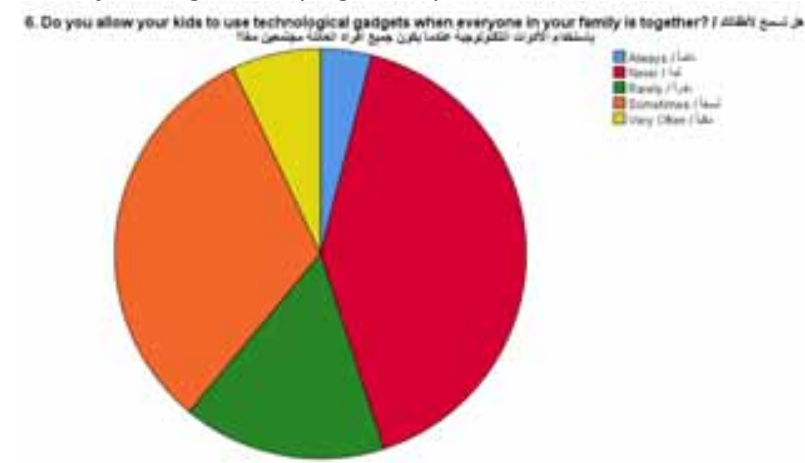

Figure 4: "Do you allow your kids to use technological gadgets when everyone in your family is together?". Answers are: 4\% Always, 41\% never; 16\% Rarely, 32\% Sometimes, $7 \%$ Very Often.

\section{CONCLUSION}

One of the major benefits of social media is connectivity between people. It enables people to express their thoughts and feelings, and to receive social support. However, it could be regarded as a 'double-edged sword'. This study has dealt with how the use of social media impacts the family and marital satisfaction in Lebanon. It is highly possible that social media are creating a society of addicts. Results of this study showed existing impact of the social media/technological devices usage on the quality of relationships between individuals. We noticed that the more time is spent on social media, the more tension in relationship is found between \# couples and family members. More than half the population were upset that their partners is distracted by their technological device when they are together. $76 \%$ says that technology makes it easier for couples to cheat. $90 \%$ of participants who have kids that use technological devices, rarely have discussion with their children because of content they posted on a social network. Despite that $76 \%$ of the population agree that the technology isolates kids from their parents. $46 \%$ don't have a home technology policy with their kids or spouse.

It is important to educate the next generation about the pros and cons associated with Social media. Moreover, educating parents about parenting methods and home technology rules plays a key role. The lack of awareness and parent control has a large influence on one's moral decision making on social media. Thus, raising awareness can help children avoid the dangers and exploit the positives aspects of Social media.

One of the possible limitations to collecting richer data in this study was that the short answer questions in the survey were vague. However, the 
data that were collected still served to be beneficial. In the future works, the various parenting styles, and their relationship with social media usage and one's personality, could be examined to give a broader understanding of the behavioural control in individuals.

\section{REFERENCES}

Clement, J. (2019) 'Number of global social network users 2010-2021'. URL: https://www.statista.com/

Gaál, Z., Szabó, L., Obermayer-Kovács, N. and Csepregi, A. (2015). 'Exploring the role of Social Media in Knowledge Sharing'. The Electronic Journal of Knowledge Management, 13 (3), pp. 185-197

Yunis Ali Ahmed, Mohammad Nazir Ahmad, Norasnita Ahmad, and Nor Hidayati Zakariaa (2019). 'Social media for knowledge-sharing: $A$ systematic literature review'. In Telematics and Informatics, Volume 37, pp. 72-112.

Dušan Mladenović, Anida Krajina, and Wioleta Kucharska, (2018). 'Social Media and Knowledge Sharing - What Do We Know So Far?' In proceedings of the 5th European Conference on Social Media, Limerick Institute of Technology, Ireland, pp. 163-170.

Saadiah Ghazali, Nor Intan Saniah Sulaiman, Nerda Zaibidi, and Rose Alinda Alias (2016). 'The impact of knowledge sharing through social media among academia'. In the 4th international conference on quantitative sciences and its applications. AIP publishing, 1782 (1), p. 30003.

Shashi Pratap Singh, Dr. A.k. Rai, Ankita Wal, Dr.Gaurav Tiwari, Ruchi Tiwari, and Asfa Parveen, (2016). 'Effect of social media in health care: uses, risks, and barriers'. World journal of pharmacy and pharmaceutical sciences, 5 (7), pp. 282-303.

Bahareh Ahadinejad, and Hadi Najafi (2017). 'Ebusiness through Social Media: A Quantitative Survey (Case Study: Instagram)'. International Journal of Management, Accounting and Economics, 4 (1), pp: 80-99.

Helena Alves, Cistina I. Fernandes, and Mario Raposo (2018). 'Social Media Marketing: A Literature Review and Implications: Implications of Social Media Marketing'. 33(12), pp.1029-1038.

C.M. van der Bank, and Marjone van der bank, (2015). 'The impact of social media: advantages or disadvantages'. In African Journal of Hospitality, Tourism and Leisure, 4 (2).

Boers E., Afzali MH., Newton N., and Conrod P. (2019). 'Association of Screen Time and Depression in Adolescence'. JAMAPediatr, 73(9) doi:10.1001/jamapediatrics.2019. 1759.

Demetrious, I. (2019). 'The smiling depression of the social media: psychological aspects of social media on mental well-being'. In 1st Panhellenic conference: Psychological Effects of Mass Media on Everyday Life. Frederick university, pp: 118-127.

Amy Orbena, Tobias Dienlinc, and Andrew K. Przybylskia (2019). 'Social media's enduring effect on adolescent life satisfaction'. In Proceedings of the National Academy of Sciences, 116 (21), pp. 10226-10228, doi: 10.1073/pnas.1902058116.

Maxwell Constantine, and Chando Musingafi (2013). 'Impact of the Facebook on Parent-Child Relationship in the African Context: the Zimbabwean Experience'. In Information and Knowledge Management, 3 (9), pp. 31-39.

Maged N. Kamel Boulos, Dean M. Giustini and Steve Wheeler (2016). 'Instagram and WhatsApp in Health and Healthcare: An Overview'. Future Internet. 8(3):37; doi: 10.3390/fi8030037.

Mowafa Househ, Elizabeth Borycki, and Andre Kushniruk (2014). 'Empowering patients through social media: The benefits and challenges'. Health Informatics Journal, 20(1), pp. 50-8.

Muqaddas Jan, Sanobia Anwar Soomro, and Nawaz Ahmad, (2017). 'Impact of Social Media on SelfEsteem'. European Scientific Journal 13(23), pp. 329-341.

Frampton, J. R., and Fox, J. (2018). 'Social Media's Role in Romantic Partners' Retroactive Jealousy: Social Comparison, Uncertainty, and Information Seeking'. Social Media + Society. doi: 10.1177/2056305118800317.

Carter, Z. A. (2015). 'Married and previously married men and women perceptions of communi-cation on Facebook with the opposite sex: How communicating through Facebook can be damaging to marriages'. 57(1), pp. 36-55.

Irum Saeed Abbasi and Nawal AlGhamadi (2017). 'When Flirting Turns Into Infidelity: The Facebook Dilemma'. American Journal of Family Therapy 45(1), pp. 1-14.

Valenzuela, S., Halpern, D., and Katz, J. E. (2014). 'Social network sites, marriage well- being and divorce: Survey and state-level evidence from the United States'. Computers in Human Behavior, 36, pp. 94-101.

Piercy, F. P., Riger, D., Voskanova, C., Chang, W., Haugen, E., and Sturdivant, L. (2015). 'What marriage and family therapists tell us about improving couple relationships through technology?' In C. J. Bruess (Ed.), Family communication in the age of digital and social media, pp. 207-227.

Betul Keles, Niall McCrae and Annmarie Grealish (2019). 'A systematic review: the influence of social media on depression, anxiety and psychological distress in adolescents'. In International Journal of Adolescence and Youth, pp. 1-15. doi : $\{10.1080 / 02673843.2019 .1590851\}$,

Jason C. Northrup, and Jessica R. Smith (2016). 'Effects of Facebook Maintenance Behaviors on Partners' Experience of Love'. Contemporary Family Therapy 38(2). pp 245-253, doi: $10.1007 / \mathrm{s} 10591-016-9379-5$ 